\title{
Wrinkle Severity Grading Scale: A Southeast Asia Study
}

\author{
Brian Tian \\ IDOC Medical Holdings, Singapore \\ Email: ^briananthonytian@gmail.com
}

How to cite this paper: Tian, B. (2018) Wrinkle Severity Grading Scale: A Southeast Asia Study. Open Access Library Journal, 5: e3757.

https://doi.org/10.4236/oalib.1103757

Received: June 22, 2017

Accepted: April 16, 2018

Published: April 19, 2018

Copyright $\odot 2018$ by author and Open Access Library Inc.

This work is licensed under the Creative Commons Attribution International License (CC BY 4.0).

http://creativecommons.org/licenses/by/4.0/

(c) (i) Open Access

\begin{abstract}
Objective wrinkle grading scales have been described for Caucasians and Japanese, but none for South-east Asians. Southeast Asians tend to be darker in skin complexion (usually skin types IV and above). A wrinkle scale using fairer Caucasian and Japanese skin, may not be easily applicable for the darker Southeast Asian skin. Therefore, in this paper, we describe and validate a wrinkle grading scale for Southeast Asians.
\end{abstract}

\section{Subject Areas}

Dermatology

\section{Keywords}

Wrinkles, Grading, Scale, Asia, Southeast Asia

\section{Introduction}

Facial wrinkles, furrows, and folds are common complaints that present to plastic surgeons, dermatologists and aesthetic doctors. There are a wide range of treatments; from topical therapies (retinoids) to injectables, to surgical facelifts. Successful treatment is usually benchmarked to patients' satisfaction. In recent times, large cosmetic and paramedical companies have developed multiple topical wrinkle treatments. A large number remain unvalidated by the scientific community. Conversely, some products have been subjected to scientific research. However, end-points of this research are mostly based on subjective expert opinions. The lack of a validated wrinkle grading scale prevents the scientific community from being able to objectively evaluate these products and their respective trials.

There have been attempts to develop formalised, objective grading scales [1] 
[2] [3] [4] [5], however these have mostly been studied in Caucasians and Japanese [6]. There is no scale described and validated for South-east Asians. Southeast Asians tend to be darker in skin complexion (usually skin types IV and above). The nature of wrinkling and response to photoaging is different. Caucasians tend to wrinkle, whereas dyspigmentation is a predominant manifestation of photoaging for Southeast Asians [7] [8]. A photo-descriptive scale using Caucasian skin, may not be easily applicable for the darker Southeast Asian skin.

Therefore, in this paper, we describe and validate a wrinkle grading scale for Southeast Asians. The aim is to devise a simple photo-descriptive standardised scale that medical professionals can agree on and utilise with ease. This is an important first step to standardising and evaluating any wrinkle treatments.

\section{Methods and Materials}

198 patients were recruited for this study. Informed consent was taken, and the study was conducted in accordance with principles of Helsinki. Only patients aged 18 years and above, with skin types IV and above were selected. Other criteria were that the patients must not have received any form of treatment or therapy on their face, no oral medications such as retinoids, and no dermatological skin conditions in the past one year.

Each patient washed his/her face with water. They were then photographed in a standard room with ambient temperature of 25 degree Celcius. A photograph of the entire face was obtained for grading, with right and left side profile shots, and separate close-up photos of the outer eye corners and the forehead. Standardization of lighting, angle, and distance was ensured. In our scale, the defintions required the patients to manually stretch their skin at the wrinkled areas, with the aim to maximally efface as much of the wrinkles as possible. Photographs were taken at the maximal stretching to compare the wrinkle depth and appearance pre and during stretching.

A descriptive and pictorial 5-grade wrinkle scale was defined (See Table 1). 5 independent dermatologists used the scale to evaluate the photographs of the 198 patients. For the determination of the reproducibility of scores, scoring was done by the same five dermatologists one week after the initial scoring. Scores were compared between the dermatologists for correlation (inter-observer). Each individual grader's score for both weeks were compared as well (intraobserver). Intra-observer and inter-observer reliability was assessed with the Fleiss kappa correlation coefficient.

\section{Results}

In this study, there were 111 females and 87 males. $86 \%$ of patients had skin type IV, while the remainder had skin type V. $93 \%$ of patients were Chinese, $3 \%$ were Malays and the remaining $4 \%$ were Indonesians. The average age of the patients was 52.8 years old (range 22 - 87).

For eye corner wrinkles, using the average of the 5 dermatologist-given scores, 
Table 1. Wrinkle severity grading system.

\begin{tabular}{|c|c|c|}
\hline Wrinkle Grade & At rest & At Rest \\
\hline 1) None & No visible fold, continuous skin line & \\
\hline 2) Mild & $\begin{array}{l}\text { Shallow but visible fold with a slight } \\
\text { indentation; minor facial feature. } \\
\text { disappears when stretched. }\end{array}$ & \\
\hline 3) Moderate & $\begin{array}{l}\text { Moderately deep folds. Clear facial } \\
\text { features visible at normal appearance } \\
\text { but disappears when stretched. }\end{array}$ & \\
\hline 4) Severe & $\begin{array}{l}\text { Very long and deep folds; prominent } \\
\text { facial feature. Less than } 2 \mathrm{~mm} \text { visible } \\
\text { fold when stretched. }\end{array}$ & \\
\hline 5) Extreme & $\begin{array}{l}\text { Extremely deep and long folds, detri- } \\
\text { mental to facial appearance. }>2 \mathrm{~mm} \\
\text { visible folds still visible even when } \\
\text { stretched. }\end{array}$ & \\
\hline
\end{tabular}

$52 \%$ of patients had grade 3 wrinkles. Whereas for the forehead, $51 \%$ of patients had grade 3 wrinkles. The kappa values amongst the 5 dermatologists, in the 
five-grade evaluation for eye corner wrinkles ranged from 0.71 to 0.88 (all $\mathrm{p}<$ 0.05). The kappa value for forehead wrinkles ranged from 0.76 to 0.92 (all $\mathrm{p}<$ 0.05 ). Intra-observer (test-retest) agreement was $89 \%$ (eye wrinkle) and $92 \%$ (forehead); kappa coefficient for the intra-observer evaluation ranged from 0.81 to $0.92($ all $\mathrm{p}<0.05)$.

All the 5 dermatologists had no prior training in our wrinkle scale. All 5 reported that they found the scale easy to interpret and applied it with ease.

\section{Discussion}

In the era of innovative aesthetic technology, there remains to be an accepted standard to grade wrinkles. Without a validated grading system, it is difficult to scientifically analyse the effect of various aesthetic techniques and products. While work has been done to evaluate various wrinkle grading systems; most of this work has been performed in Caucasians. Griffiths et al [7] and Larnier et al [8] suggested that a typical photo-descriptive wrinkle scale would not be applicable for Asians. The reason was that Asians typically experience dyspigmentation as a consequence of photoaging. Therefore a dedicated wrinkle scale would not truly reflect the degree of photoaging for Asians. This would have been an accurate description if aging alone, was evaluated. However, in this respect, we are focusing on the development of a dedicated wrinkle scale. This is because in present times, there are dedicated wrinkle-only treatment solutions (Botox, fillers). The effect of dyspigmentation has no immediate bearing in the decision to offer Asian patients these modalities of treatment. However, existing wrinkle scales would not be applicable since most of the photographic standards are based on Caucasian skin. The appearance of wrinkles on fairer skin and thus the judgement of its severity would be vastly different.

Therefore in our paper, our aim was to demonstrate that a simple photo-descriptive scale can be applied to Southeast Asians. Our kappa coefficients demonstrated that this scale is easily reproducible and highly agreeable when used to evaluate Southeast Asians. While this study confirms a grading system can be used, its main limitation is that it is yet to be correlated to actual clinical changes.

As a follow up on this study, we plan to conduct an even larger study to demonstrate reproducibility and ease of use of this scale. Subsequently, it would be useful to apply this scale to a clinical trial where Botox or other wrinkle treatments are used. This would enable us to validate if the scale is sensitive enough to detect wrinkle changes pre and post-treatment (for proven treatments). Finally, this scale can be analysed in conjunction with histological samples (via skin biopsies) to demonstrate further clinical correlation. Lastly, the photo-descriptive scale should be expanded to include wrinkles at other facial sites, to enable it to be more comprehensive.

\section{References}

[1] Weiss, J.S., Ellis, C.N., Headington, J.T., Tincoff, T., Hamilton, T.A. and Voorhees, 
J.J. (1988) Topical Tretinoin Improves Photoaged Skin. JAMA, 259, 527-532. https://doi.org/10.1001/jama.1988.03720040019020

[2] Leyden, J.J., Grove, G.L., Grove, M.J., Thorne, E.G. and Lufrano, L. (1989) Treatment of Photodamaged Facial Skin with Topical Tretinoin. Journal of the American Academy of Dermatology, 21, 638-644. https://doi.org/10.1016/S0190-9622(89)70231-0

[3] Lever, L., Kumar, P. and Marks, R. (1990) Topical Retinoic Acid for Treatment of Solar Damage. British Journal of Dermatology, 122, 91-98. https://doi.org/10.1111/j.1365-2133.1990.tb08244.x

[4] Grove, G.L., Grove, M.J., Leyden, J.J., Lufrano, L., Schwab, B., Perry, B.H. and Thorne, E.G. (1991) Skin Replica Analysis of Photo Damaged Skin after Therapy with Tretinoin Emollient Cream. Journal of the American Academy of Dermatology, 25, 231-237. https://doi.org/10.1016/0190-9622(91)70187-7

[5] Griffiths, C.E.M., Kang, S., Ellis, C.N., Kim, K.J., Finkel, L.J., Ortiz-Ferrer, L.C., White, G.M., Hamilton, T.A. and Voorhees, J.J. (1995) Two Concentrations of Topical Tretinoin (Retinoic Acid) Cause Similar Improvement of Photoaging But Different Degrees of Irritation. Archives of Dermatology, 131, 1037-1044. https://doi.org/10.1001/archderm.1995.01690210067011

[6] Tsukahara, K., Takema, Y., Kazama, H., Yorimoto, Y., Fujimura, T., Moriwaki, S., Kitahara, T., Kawai, M. and Imokawa, G. (2000) A Photographic Scale for the Assessment of Human Facial Wrinkles. Journal of Cosmetic Science, 51, 127-139.

[7] Griffiths, C.E.M., Wang, T.S., Hamilton, T.A., Voorhees, J.J. and Ellis, C.N. (1992) A Photonumeric Scale for the Assessment of Cutaneous Photodamage. Archives of Dermatology, 128, 347-351. https://doi.org/10.1001/archderm.1992.01680130061006

[8] Larnier, C., Ortonne, J.P., Venot, A., Faivre, B., Beani, J.C., Thomas, P., Brown, T. and Sendagorta, E. (1994) Evaluation of Cutaneous Photodamage Usinga Photographic Scale. British Journal of Dermatology, 130, 167-173. https://doi.org/10.1111/j.1365-2133.1994.tb02895.x 